\title{
Distal Splenorenal Shunt (DSRS) in Children with Extrahepatic Portal Hypertension
}

\author{
Zia Ur Rehman 1 and Zafar Nazir2 \\ Section of Vascular Surgeryl / Pediatric Surgery², Department of Surgery, The Aga Khan University Hospital (AKUH), Karachi, Pakistan
}

\begin{abstract}
Portal hypertension $(\mathrm{PH})$ is infrequent in children as compared to adults. Currently, repetitive endoscopic ablation of varices is standard treatment. However, endoscopic facilities are not readily available in resource-limited settings. We reviewed the indications, operative morbidity, mortality, shunt patency and re-bleeding episodes in nine patients (age range 6-16 years, M:F 6:3) who had DSRS for recurrent GI bleeding not responding to endoscopic treatment and hypersplenism. DSRS is a safe and effective treatment alternative in resource limiting setting for preventing bleeding and improving hypersplenism in children with extrahepatic portal hypertension.
\end{abstract}

Key Words: Children, Portal hypertension, Esophageal varices, Gl bleeding, Distal splenorenal shunt (DSRS).

How to cite this article: Rehman ZU, Nazir Z. Distal splenorenal shunt (DSRS) in children with extrahepatic portal hypertension. $J$ Coll Physicians Surg Pak 2019; 29(12):1228-1229.

Extra-hepatic portal vein obstruction (EHPVO) is the cause in majority of cases of portal hypertension $(\mathrm{PH})$ in children. It is usually idiopathic and is also reported following umbilical vessel catheterisation in infancy or biliary atresia surgery. Currently, medical and repetitive sclerotherapy is the recommended management of portal hypertension. However, up to $15 \%$ of children may require shunt surgery. Shunt surgery offers one-time solution to recurrent $\mathrm{Gl}$ bleeding and hypersplenism.1 However, in pediatric age the procedure is technically demanding due to small calibre veins. This study evaluates indications, morbidity and patency of DSRS in children with portal hypertension.

After ERC (ethical review committee) approval (20190749-2321), medical records of pediatric patients (<18 years) who had DSRS from January 1995 to December 2018 at The Aga Khan University Hospital, Karachi (Pakistan) were reviewed for patient demographics, indication of procedure, imaging, laboratory investigations, operative time, morbidity, hospital stay, shunt patency and episodes of recurrent bleeding. Outcomes measures were prevention from repeat bleeding episodes and improvement in platelet counts.

Data was analysed in SPSS version 22. Quantitative variables were reported as means and/or medians. Frequency was reported for categorical variables. Difference in outcome variables were assessed through paired t-test.

Correspondence to: Dr. Zia Ur Rehman, Section of Vascular Surgery, Department of Surgery, The Aga Khan University

Hospital, Stadium Road, Karachi-74800, Pakistan

E-mail: ziaur.rehman@aku.edu

Received: February 28, 2019; Revised: April 29, 2019;

Accepted: May 20, 2019
Median age of nine patients was $11(6-16)$ years. Most were males (6:3). All patients had history of upper gastrointestinal bleeding including $4(44.4 \%)$ patients having multiple episodes. Median sclerotherapy sessions before shunt procedures were $2(0-4)$. All patients had normal liver function tests. The procedures were performed under general anaesthesia through transverse upper abdominal incision. The splenic vein was mobilised from its junction with superior mesenteric vein to a length which can easily be brought to the left renal vein to create a tension-free and supple end-to-side anastomosis. The mean operative time was $263 \pm 22.2$ minutes. Routine postoperative monitoring and care was provided. There were no operative complications including bleeding, injury to the surrounding structures, wound infection, or encephalopathy. The mean hospital stay was $8.8 \pm 1.26$ days. Patients were followed three monthly during first postoperative year and then annually, both clinically and with ultrasound doppler. Graft was considered patent if it showed flow from portal venous system to renal vein.

Median follow-up was 3 (1-10) years. Mean preoperative platelets improved from $57.3 \pm 22.2$ to $94.3 \pm 34.4 \times 109 /$ l $(p=0.005)$ and splenic size decreased from $15.6 \pm 2.39$ to $15.03 \pm 2.46 \mathrm{~cm}$ ( $p=0.692$, Table I). Most patients (88.8\%) had no $\mathrm{Gl}$ bleeding episode. One patient had bleeding 6 months after the surgery which required a session of sclerotherapy. Shunts were patent on last follow-up except in one patient whose shunt was noted to be

Table I: Comparison of pre- and post-outcome parameters.

\begin{tabular}{l|c|c|c}
\hline Variables & $\begin{array}{c}\text { Preoperative } \\
\text { Mean } \pm(\mathrm{SD})\end{array}$ & $\begin{array}{c}\text { Postoperative } \\
\text { Mean } \pm(\mathrm{SD})\end{array}$ & $\mathrm{p}$-value \\
\hline Bleeding episodes & $9(100 \%)$ & $1(11.1 \%)$ & $<0.001$ \\
Platelets count $(\mathrm{x} \mathrm{109} / \mathrm{I})$ & $57.4 \pm 22.2$ & $94.4 \pm 34.4$ & 0.005 \\
Spleen size $(\mathrm{cm})$ & $15.6 \pm 2.4$ & $15.1 \pm 2.5$ & 0.692 \\
\hline
\end{tabular}


blocked at 6-month follow-up. She had protein $\mathrm{C}$ and $\mathrm{S}$ deficiency and had small calibre vein $(4 \mathrm{~mm})$ and dissection was difficult due to the previous episode of pancreatitis. Another patient required splenectomy, two years after the procedure for persistent hypersplenism (low platelets and increasing transfusion requirements to maintain hemoglobin levels).

EHPVO (extra-hepatic portal vein obstruction) is usually the cause of portal hypertension in children and it manifests with hematemesis and hypersplenism. Most patients are treated with repeated sclerotherapy and pharmacotherapy such as propranolol. In cases, which are refractory to endoscopic treatment, DSRS is a preferable alternative as it provides efficient and longlasting decompression of the portal venous system. The reported cases of children managed with DSRS illustrate that it is effective in preventing recurrent bleeding and resolution of hypersplenism; and can safely be offered in a developing country where access to medical care is suboptimal. However, we observed that shunt surgery should not be offered in children with previous history of severe pancreatitis or hypercoagulable state.

There are several misconceptions about shunt surgery in pediatric age group, e.g. high failure rates in children under 10 years, particularly those whose veins are less than $10 \mathrm{~mm}$ in diameter. The other is that bleeding episodes in such children should be managed conservatively until they grow out of the disease by development of collateral circulation. There is no longterm data to support these impressions. ${ }^{2}$

Many studies have demonstrated that shunts can successfully be offered to children of any age with minimal morbidity as success rate around $90 \%$, as is reported in different series. ${ }^{3}$ Orloff et al. have reported $97 \%$ patency and thrombosis in less than $5 \%$ of patients. 4 Similarly, Laurtz et al. reported remarkable outcome in terms of prevention of recurrent $\mathrm{GI}$ bleeding. ${ }^{5}$ Recently, Paloma et al. and Patel et al. have shown effectiveness of DSRS in children.1,6 Moreover, shunts are cost-effective, psychologically less traumatic than the repeated endoscopic procedures, and favour normal physical growth in children.
In conclusion, though this is a retrospective study from a single centre with a small number of patients, it demonstrates that shunt surgery is safe and reliable alternative to repeated endoscopic procedures; for prevention of bleeding and to improve hypersplenism in children with extrahepatic portal hypertension.

\section{AUTHORS' CONTRIBUTION:}

ZUR: Study concept, data collection, writing, critical review and revision; final approval of the article and accountability of all aspects of the article.

ZN: Study concept, critical review and revision; final approval of the article and accountability of all aspects of the article.

\section{CONFLICT OF INTEREST:}

Authors declared no conflict of interest.

\section{REFERENCES}

1. Triana Junco $P$, Alvarez A, Dore $M$, Jimenez Gomez J, Sánchez Galán A, Vilanova-Sánchez A, et al. Long-term results after diversion surgery in extrahepatic portal vein obstruction. Eur J Pediatr Surg 2019; 29:23-7.

2. Sharma N, Bajpal M, Kumar A, Paul S, Jana M. Portal hypertension: A critical appraisal of shunt procedures with emphasis on distal splenorenal shunt in children. $J$ Indian Assoc Pediatr Surg 2014; 19:80-4.

3. Shneider BL, de Ville de Goyet J, Leung DH, Srivastava A, Ling SC, Duché $M$, et al. Primary prophylaxis of variceal bleeding in children and the role of MesoRex Bypass: summary of the Baveno VI Pediatric stalellite symposium. Hepatology 2016; 63:1368-80.

4. Orloff MJ, Orloff MS, Rambotti M. Treatment of bleeding esophagogastric varices due to extrahepatic portal hypertension: Results of portal-systemic shunts during 35 years. J Pediatr Surg 1994; 29:142-51.

5. Lautz TB, Keys LA, Melvin JC, Ito J, Superina RA. Advantages of the meso-Rex bypass compared with portosystemic shunts in the management of extrahepatic portal vein obstruction in children. J Am Coll Surg 2013; 21:83-9.

6. Patel N, Grieve A, Hiddema J, Botha J, Loveland J. Surgery for portal hypertension in children: A 12-year review. S Afr Med J 2017; 107:S12-5. 